\title{
Low versus standard dose intravenous alteplase in the treatment of acute ischemic stroke in Egyptian patients
}

Gelan M. Salem, MD, Wafik M. El-Sheik, MD, Basma G. El-shanawany, MBBCH, Khaled H. Afif, MD.

\begin{abstract}
الأهداف : لتقييم نتيجة جرعة منخفضضة من التيباز وسلامتها

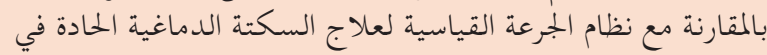
المرضى المصريين.

المنهجية : أجريت دراسة رصدية استطلاعية غير عشوائية منفردة

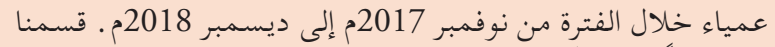

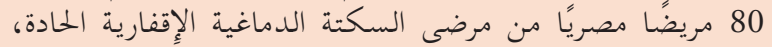

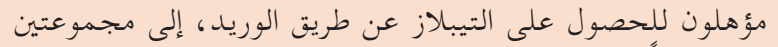

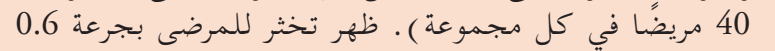

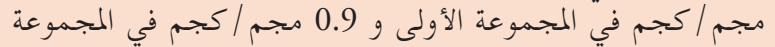

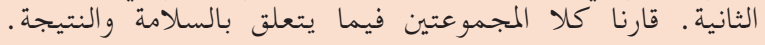

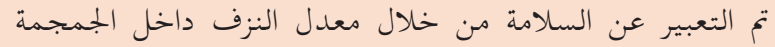

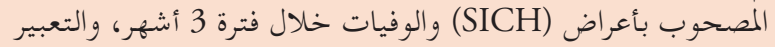

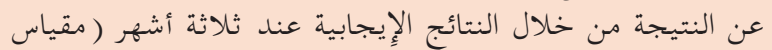

رانكين المعدل[mRS] من 0 إلى 2 2 )

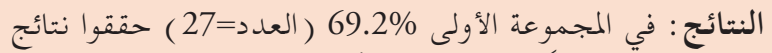

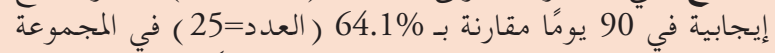

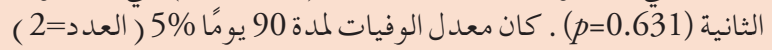

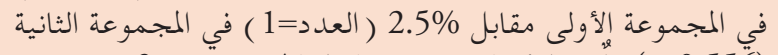

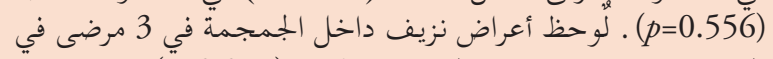

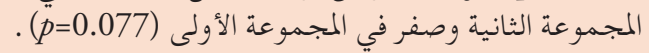

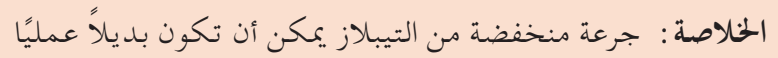

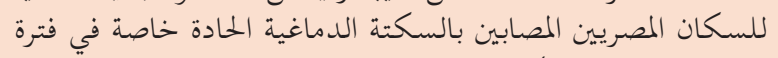
تتراوح من 3 إلى 4.5 ساعات . لماين بالـ
\end{abstract}

Objectives: To assess low dose altepase outcome and safety in comparison with a standard-dose regimen for acute ischemic stroke treatment in Egyptian patients.

Materials: An observational prospective cohort nonrandomized single blinded study was carried out during the period from November 2017 to December 2018. Eighty Egyptian acute ischemic stroke patients, all eligible for intravenous alteplase, were subdivided into 2 groups (40 patients in each group). Patients were thrombolysed at a dose of $0.6 \mathrm{mg} / \mathrm{kg}$ in the first group and $0.9 \mathrm{mg} / \mathrm{kg}$ in the second group. Both groups were compared in regard to safety and outcome. Safety was expressed by the rate of symptomatic intracranial hemorrhage (SICH) and 3 months mortality, while outcome was expressed by favorable outcomes at three months (modified Rankin Scale [mRS] of 0 to 2).

Results: In the first group, 69.2\% ( $\mathrm{n}=27)$ achieved favorable outcomes at 90 days compared with $64.1 \%$ $(\mathrm{n}=25)$ in the second group $(p=0.631)$. Ninety-day mortality was $5 \%(\mathrm{n}=2)$ in the first group versus $2.5 \%$ $(\mathrm{n}=1)$ in the second group $(p=0.556)$. Symptomatic intracranial hemorrhage was noted in 3 patients in the second group and zero patients in the first group $(p=0.077)$.

Conclusion: Low-dose alteplase could be a practical alternative for Egyptian populations with acute ischemic stroke especially in 3 to 4.5 hours window.

Neurosciences 2021; Vol. 26 (2): 179-185 doi: 10.17712/nsj.2021.2.20200148

From the Neuro-Psychiatry Department (Salem, El-Sheik, Afifi), Menoufia University, Menoufia; from the Mataria Teaching Hospital (El-shanawany), Mataria, Egypt,

Received 2nd October 2020. Accepted 30th November 2020.

Address correspondence and reprint request to: Dr. Gelan M. Salem, Department of Neuropsychiatry, University of Menoufia, Menoufia, Egypt E-mail:d.gelan1981@gmail.com

ORCID ID: https://orcid.org/0000-0002-1092-099X

Cerebrovascular stroke is the second death and

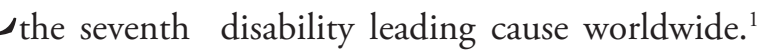
Tissue-type plasminogen activator (tPA) alteplase was the first medication approved by the Food and Drug Administration (FDA) for the acute ischemic stroke (AIS) treatment on June 1996, within 3 hours of stroke onset with a recommended dose of $0.9 \mathrm{mg} / \mathrm{kg}$ (maximum $90 \mathrm{mg}$ ). ${ }^{2}$ In 2008 , the safety of using alteplase within 3 to 4.5 hours of stroke onset was approved by the Safe 
Implementation of Treatments in Stroke International Stroke Thrombolysis Registry (SITS -ISTR) ${ }^{3}$ and the European Cooperative Acute Stroke Study (ECASS III). ${ }^{4}$ However, thrombolytic therapy use has not been widely adopted, especially in developing countries. The restricted time window (3 to 4.5 hours), intracerebral hemorrhage $(\mathrm{ICH})$ risk and the drug high cost are major obstacles preventing its broad application. ${ }^{5}$ Coagulation and fibrinolysis responses differ among different races, which increase symptomatic intracerebral hemorrhage $(\mathrm{SICH})$ risk with standard-dose alteplase ${ }^{6}$ in Asian populations, many Asian neurologists considered alteplase low dose to be a better alternative for ischemic stroke treatment. Many studies had been conducted in order to prove the efficacy and safety of Alteplase low dose. $^{7-9}$ One of these studies was the Japan Alteplase Clinical Trial (J-ACT) conducted by Yamaguchi et a ${ }^{10}$ According to this study, using a $0.6 \mathrm{mg} / \mathrm{kg}$ dose of intravenous recombinant tissue plasminogen activator (rtPA) in Japanese patients was safe and effective. Despite the relatively stroke high rate among Egyptian populations, 963/100,000 inhabitants, only less than $1 \%$ of stroke patients receive intravenous thrombolysis. A major reason for this is the drug cost. ${ }^{11,12}$ Low-dose regimens $(0.6 \mathrm{mg} / \mathrm{kg})$ use will lower the economic burden of thrombolytic therapy in the community and will greatly promote the implementation of this therapy in Egypt. Our study aim was to assess the outcome and safety of alteplase low dose in comparison to the standard-dose regimen in AIS treatment in Egypt.

Methods. This study was an observational prospective cohort non-randomized single blinded study done during the period from November 2017 to December 2018. Eighty ischemic stroke patients within four and a half hours from symptom onset were recruited from both El-Mataria Teaching Hospital and Menoufia University Hospital. This study was approvad by the Research and Ethics Committee of the Faculty of Medicine, Menoufia University. All patients were considered eligible for intravenous thrombolysis according to the American Heart Association (AHA) and American Stroke Association (ASA) guidelines with inclusion criteria which are: age $\geq 18$ years old, time window $\leq 4.5$ hours, patients presented with moderate to severe symptoms and demonstrate early

Disclosure. Authors have no conflict of interests, and the work was not supported or funded by any drug company. improvement before starting alteplase, patients with seizures at time of onset if evidence suggests that residual impairment is secondary to stroke and not a postictal phenomenon, patients with blood pressure $\leq 185 / 110$ or those who presented with high blood pressure and responded successfully to intravenous antihypertensive and patients with early ischemic changes (other than obvious hypodensity) as demonstrated on initial noncontrast CT brain. ${ }^{13}$ Informed written consent forms for alteplase were signed by patients or first-degree relatives. All patients were subjected to complete history taking, including assessment of vascular risk factors, previous treatment, time window, pre-stroke modified Rankin Scale (mRS), and initial stroke severity measured as a National Institutes of Health Stroke Study (NIHSS) score. Non-contrast computed tomography (CT) brain scans were done in all patients upon presentation, and these scans were analyzed for the presence of intracranial hemorrhage or any findings preventing thrombolysis. Alberta Stroke Program Early CT (ASPECT) scores were used to assess early signs of ischemia. ${ }^{14}$ Trial of ORG 10172 in acute stroke treatment (TOAST) ${ }^{15}$ and Oxfordshire community stroke project (OCSP) ${ }^{16}$ classifications to clarify stroke subtypes. The patients were assigned to treatment groups non-randomly. The first group was given a single dose of intravenous alteplase as a low dose of $0.6 \mathrm{mg} / \mathrm{kg}$ (not exceeding $60 \mathrm{mg}$ ), with $10 \%$ given as a bolus followed by a continuous infusion of the remainder over one hour. We give the low dose to patients who are more risky to haemorragic transformation as old age, when we suspect large infarction and those with time window more than $3 \mathrm{~h}$ and less than $4.5 \mathrm{~h}$. The second group was given a standard dose of $0.9 \mathrm{mg} / \mathrm{kg}$ (not exceeding $90 \mathrm{mg}$ ), with $10 \%$ given as a bolus followed by a continuous infusion of the remainder over one hour. Alteplase infusion and monitoring for complications over the next 24 hours were done following AHA/ASA guidelines. ${ }^{13}$ Follow-up non-contrast CT brain scans 24 hours post treatment were assessed for ICH. The NIHSS was assessed 24 hours after treatment and at day seven of admission or at discharge. In-hospital mortality was recorded. All patients were followed-up with 90 days from admission by telephone calls or face-to-face interviews to assess $\mathrm{mRS}$ and mortality.

Primary objectives. 1) Assessment safety of low-dose and standard-dose alteplase by assessing the incidence of symptomatic intracranial hemorrhage ( $\mathrm{SICH}$ ) within 24 hours of starting treatment and assessing mortality (in-hospital mortality and 90-day mortality). We defined SICH according to the ECASS study definition (any hemorrhage plus a neurological deterioration of $\geq$ 4 points from the NIHSS baseline or from the lowest 
NIHSS value after baseline for seven days, or leading to death). ${ }^{4}$

2) Assessment of outcome of low-dose and standarddose alteplase by assessing the proportion of patients with favorable outcomes ( $m R S$ scores of 0 to 2 ) and unfavorable outcome (mRS scores of 3 to 6) at 90 days.

Secondary objectives. An assessment was made regarding predictors of favorable outcomes ( $\mathrm{mRS}$ scores of 0 to 2 ).
Statistical methods. Results were collected, tabulated, and statistically analyzed by IBM personal computer and the Statistical Package for the Social Sciences (SPSS) version 22 (Armonk, NY: IBM Corp, 2013). Data were presented as descriptive statistics including percentage $(\%)$, mean $(\mathrm{x})$, standard deviation $(\mathrm{SD})$, and range. Statistical tests used included the Chi-square test $(\chi 2)$, the Student's t-test, the Mann-Whitney test, the Wilcoxon Signed Rank test, and binary

Table 1 - Demographic and baseline characteristics of patients treated with IV tissue-type plasminogen activator (tPA) in low dose and standard dose groups.

\begin{tabular}{|c|c|c|c|c|c|}
\hline Items & $\begin{array}{l}\text { Low dose } \\
(\mathrm{n}=40)\end{array}$ & $\begin{array}{l}\text { Standard dose } \\
\quad(n=40)\end{array}$ & $\begin{array}{l}\text { Total } \\
(\mathrm{n}=80)\end{array}$ & $\chi^{2}$ & $P$-value \\
\hline Age Mean \pm SD & $60.58 \pm 14.16$ & $61.03 \pm 8.49$ & $60.80 \pm 11.60$ & $\mathrm{t}=0.17$ & 0.864 \\
\hline $\begin{array}{l}\text { Gender } \\
\quad \text { Males } \\
\text { Females }\end{array}$ & $\begin{array}{l}22(55.0) \\
18(45.0)\end{array}$ & $\begin{array}{l}30(75.0) \\
10(25.0)\end{array}$ & $\begin{array}{l}52(65.0) \\
28(35.0)\end{array}$ & $\chi^{2}=3.52$ & 0.061 \\
\hline Current smokers & $16(40.0)$ & $21(52.5)$ & $37(46.3)$ & 1.26 & 0.262 \\
\hline Hypertension & $26(65.0)$ & $26(65.0)$ & $52(65.0)$ & -- & -- \\
\hline Diabetes mellitus & $19(47.5)$ & $12(30.0)$ & $31(38.8)$ & 2.58 & 0.108 \\
\hline Dyslipidemia & $14(35.0)$ & $15(37.5)$ & $29(36.2)$ & 0.49 & 0.485 \\
\hline Previous stroke & $5(12.5)$ & $4(10.0)$ & $9(11.3)$ & 0.13 & 0.723 \\
\hline $\mathrm{AF}$ & $12(30.0)$ & $6(15.0)$ & $18(22.5)$ & 2.58 & 0.108 \\
\hline IHD & $12(30.0)$ & $13(32.5)$ & $25(31.3)$ & 0.06 & 0.809 \\
\hline NIHSS on admission (Mean \pm SD) & $12.58 \pm 4.37$ & $14.03 \pm 4.17$ & $13.30 \pm 4.31$ & $\mathrm{t}=1.52$ & 0.133 \\
\hline $\begin{array}{l}\text { Time to treatment (hours) } \\
\quad 0-3 \\
3-4.5\end{array}$ & $\begin{array}{r}4(10.0) \\
36(90.0)\end{array}$ & $\begin{array}{rr}39 & (97.5) \\
1 \quad(2.5)\end{array}$ & $\begin{array}{r}43(53.8) \\
4(5.0)\end{array}$ & $\chi^{2}=61.60$ & $<0.001^{*}$ \\
\hline $\begin{array}{l}\text { Previous treatment } \\
\text { Antiplatelet drugs } \\
\text { Warfarin anticoagulant }\end{array}$ & $\begin{array}{r}12(30.0) \\
4(10.0)\end{array}$ & $\begin{array}{ll}3 & (7.5) \\
2 & (5.0)\end{array}$ & $\begin{array}{r}15(18.8) \\
6 \quad(7.5)\end{array}$ & $\begin{array}{l}3.22 \\
0.72\end{array}$ & $\begin{array}{l}0.023^{*} \\
0.396\end{array}$ \\
\hline $\begin{array}{l}\text { Prestroke } m R S \\
\text { Score } 0 \\
\text { Score } 1 \\
\text { Score } 2\end{array}$ & $\begin{array}{r}34(85.0) \\
2(5.0) \\
4(10.0)\end{array}$ & $\begin{array}{rr}35 & (87.5) \\
3 & (7.5) \\
2 & (5.0)\end{array}$ & $\begin{array}{rr}69 & (86.0) \\
5 & (6.0) \\
6 & (7.5)\end{array}$ & 0.88 & 0.644 \\
\hline Early signs of ischemia & $6(15.0)$ & $4(10.0)$ & $10(12.5)$ & 0.46 & 0.499 \\
\hline ASPECT score $($ Mean $\pm S D)$ & $6.83 \pm 3.09$ & $5.55 \pm 2.59$ & $6.19 \pm 2.90$ & $\mathrm{U}=2.00$ & $0.049^{*}$ \\
\hline $\begin{array}{l}\text { TOAST classification } \\
\text { Cardio embolic } \\
\text { Lacunar } \\
\text { Large artery } \\
\text { Other determined } \\
\text { Undetermined }\end{array}$ & $\begin{array}{r}12(30.0) \\
18(45.0) \\
14(35.0) \\
0 \\
1(2.5)\end{array}$ & $\begin{array}{r}7(17.5) \\
14(35.0) \\
9(22.5) \\
1 \quad(2.5) \\
4(10.0)\end{array}$ & $\begin{array}{rr}19 & (23.8) \\
32 & (40.0) \\
23 & (28.8) \\
1 & (1.3) \\
5 & (6.3)\end{array}$ & $\begin{array}{l}1.73 \\
0.83 \\
1.53 \\
1.01 \\
1.92\end{array}$ & $\begin{array}{l}0.189 \\
0.361 \\
0.217 \\
0.314 \\
0.166\end{array}$ \\
\hline $\begin{array}{l}\text { Oxfordshire classification } \\
\text { LACI } \\
\text { PACI } \\
\text { POCI } \\
\text { TACI }\end{array}$ & $\begin{array}{r}14(35.0) \\
13(32.5) \\
8(20.0) \\
5(12.5)\end{array}$ & $\begin{array}{r}15(37.5) \\
16(40.0) \\
0 \\
9(22.5)\end{array}$ & $\begin{array}{r}29(36.3) \\
29(36.3) \\
8(10.0) \\
14(17.5)\end{array}$ & $\begin{array}{l}0.05 \\
0.49 \\
8.89 \\
1.39\end{array}$ & $\begin{array}{l}0.816 \\
0.485 \\
0.003^{*} \\
0.239\end{array}$ \\
\hline
\end{tabular}

Values are presented as number and percentage (\%).

AF - atrial fibrillation, IHD: ischemic heart disease, NIHSS: National Institute of Health Stroke Scale,

mRS - modified rankin scale, ASPECT - Alberta Stroke Program Early CT Score, U - Mann-Whitney test, TOAST - Trial of ORG 10172 in Acute Stroke Treatment, LACI - lacunar infarction, PACI - partial anterior circulation infarction, TACI - total anterior circulation infarction,

POCI - posterior circulation infarction 
Table 2 - Comparison between low dose and standard dose Alteplase treated acute ischemic stroke patients regarding hemorrhagic transformation after treatment.

\begin{tabular}{lccccc}
\hline Items & $\begin{array}{c}\text { Low dose } \\
(\mathbf{n}=\mathbf{4 0})\end{array}$ & $\begin{array}{c}\text { Standard dose } \\
(\mathbf{n}=\mathbf{4 0})\end{array}$ & $\begin{array}{c}\text { Total } \\
(\mathbf{n}=\mathbf{8 0})\end{array}$ & $\chi^{2}$ & $P$-value \\
\hline Hemorrhagic transformation & $1(2.5)$ & $5(12.5)$ & $6(7.5)$ & 2.88 & 0.090 \\
Symptomatic ICH & 0 & $3(7.5)$ & $3(3.8)$ & 3.12 & 0.077 \\
Asymptomatic ICH & $1(2.5)$ & $2(5.0)$ & $3(3.8)$ & 0.35 & 0.556 \\
Parenchymal hemorrhage 1 & $1(2.5)$ & $2(5.0)$ & $3(3.8)$ & 0.35 & 0.556 \\
Parenchymal hemorrhage 2 & 0 & $3(7.5)$ & $3(3.8)$ & 3.12 & 0.077 \\
\hline
\end{tabular}

Values are presented as number and percentage (\%). ICH - intracranial hemorrhage

Table 3 - Comparison between low dose and standard dose Alteplase treated acute ischemic stroke patients regarding their outcome of treatment assessed by modified rankin scale (mRS) at 3 months and prevalence of deaths.

\begin{tabular}{|c|c|c|c|c|c|}
\hline Items & Low dose $(n=40)$ & $\begin{array}{l}\text { Standard dose } \\
\quad(n=40)\end{array}$ & $\begin{array}{l}\text { Total } \\
(\mathbf{n}=80)\end{array}$ & $\chi^{2}$ & $P$-value \\
\hline \multicolumn{6}{|l|}{ Outcome } \\
\hline Favorable & $27(67.5)$ & $25(62.5)$ & $52(65.0)$ & 0.23 & 0.631 \\
\hline \multicolumn{6}{|l|}{ Death } \\
\hline In hospital & $1 \quad(2.5)$ & $1 \quad(2.5)$ & $2(2.5)$ & -- & --- \\
\hline Within 3 months & $2(0.5)$ & $1(2.5)$ & $3(3.8)$ & 0.35 & 0.556 \\
\hline Overall deaths & $3 \quad(7.5)$ & $2(5.0)$ & $5(6.3)$ & 0.21 & 0.644 \\
\hline
\end{tabular}

Values are presented as number and percentage (\%). Favorable outcome: mRS from 0-2

Table 4 - Binary logistic regression analysis for predictors of favorable outcome at 3 months.

\begin{tabular}{|c|c|c|c|c|c|}
\hline \multirow[t]{2}{*}{ Variables } & \multirow[t]{2}{*}{ B } & \multirow[t]{2}{*}{ P-value } & \multirow[t]{2}{*}{ OR } & \multicolumn{2}{|c|}{$95 \% \mathrm{CI}$} \\
\hline & & & & Lower & Upper \\
\hline Age & -0.041 & 0.347 & 0.960 & 0.881 & 1.046 \\
\hline Gender (male) & 1.209 & 0.307 & 3.352 & 0.329 & 34.195 \\
\hline DM & 1.032 & 0.288 & 2.806 & 0.418 & 18.845 \\
\hline HTN & -1.098 & 0.143 & 0.333 & 0.077 & 1.449 \\
\hline Smoking & 0.037 & 0.972 & 1.038 & 0.130 & 8.312 \\
\hline Dyslipidemia & -1.364 & 0.094 & 0.256 & 0.052 & 1.260 \\
\hline Previous stroke & 0.535 & 0.804 & 1.707 & 0.025 & 115.316 \\
\hline $\mathrm{AF}$ & 20.969 & 1.000 & 127.287 & 0.000 & - \\
\hline IHD & -0.081 & 0.929 & 0.923 & 0.157 & 5.429 \\
\hline Single antiplatelets & 2.592 & 0.082 & 13.360 & 0.718 & 248.528 \\
\hline Double antiplatelets & 0.503 & 0.783 & 1.654 & 0.046 & 59.316 \\
\hline Anticoagulant & -0.953 & 0.549 & 0.386 & 0.017 & 8.686 \\
\hline Time window 3 hours & 2.271 & 0.089 & 9.684 & 0.707 & 132.667 \\
\hline $\mathrm{tPA}(0.9)$ & -0.912 & 0.504 & 0.402 & 0.028 & 5.824 \\
\hline NIHSS $(\leq 13)$ & -2.338 & 0.018 & 0.097 & 0.014 & 0.673 \\
\hline Sign ischemia (1) & 1.821 & 0.129 & 6.179 & 0.587 & 65.051 \\
\hline Old stroke & -1.867 & 0.334 & 0.155 & 0.004 & 6.800 \\
\hline TOAST (cardioembolic) & -18.096 & 1.000 & 0.000 & 0.000 & - \\
\hline TOAST (lacunar) & 24.512 & 0.999 & 44183383884.966 & 0.000 & - \\
\hline TOAST (large artery) & 3.084 & 0.151 & 21.849 & 0.326 & 1463.972 \\
\hline TOAST(other determined) & -19.249 & 1.000 & 0.000 & 0.000 & - \\
\hline Oxford (LACI) & -21.197 & 0.999 & 0.000 & 0.000 & - \\
\hline Oxford (PACI) & 1.897 & 0.179 & 6.666 & 0.419 & 106.126 \\
\hline Oxford (POCI) & -19.361 & 0.999 & 0.000 & 0.000 & . \\
\hline Symptom $\mathrm{Hg}$ & -20.131 & 0.999 & 0.000 & 0.000 & - \\
\hline
\end{tabular}

B - beta coefficient, OR - odd's ratio, CI - confidence interval, ICH - intracranial hemorrhage, DM - diabetes mellitus,

HTN - hypertension, AF - atrial fibrillation, IHD - ischemic heart disease, NIHSS - National Institute of health stroke scale, TOAST - Trial of ORG 10172 in Acute Stroke Treatment, LACI - lacunar infarction, PACI - partial anterior circulation infarction, POCI - posterior circulation infarction, tPA - Tissue-type plasminogen activator 
logistic regression. A $p$-value of $<0.05$ was considered statistically significant.

Results. Half of the study population (40 patients) received a standard dose of alteplase $(0.9 \mathrm{mg} / \mathrm{kg})$ and another 40 patients received a low dose $(0.6 \mathrm{mg} / \mathrm{kg})$. Basal characteristics of both groups are shown in (Table 1). The mean age of the study population was $60.80 \pm 11.60$ years, with male predominance in both groups. There was no significant difference between the low and standard-dose groups regarding vascular risk factors (hypertension, diabetes mellitus, dyslipidemia, smoking, ischemic heart disease, or history of previous cerebrovascular stroke). Hypertension was the most prevalent risk factor in both groups (65\% in each). There was no significant difference regarding patients number taking warfarin anticoagulant in both groups $(p=0.396)$. The initial stroke severity (assessed by National Institute of health stroke scale [NIHSS $]^{17}$ ) did not significantly differ between both groups, with a moderate stroke severity prevalent in both the low and standard-dose groups $(12.58 \pm 4.37$ versus $14.03 \pm 4.17$ respectively, $p=0.133)$.

Thirty-six patients $(90 \%)$ in the low-dose group received alteplase between 3 and 4.5 hours of stroke onset, while $97.5 \% \quad(\mathrm{n}=39)$ of the standard-dose group received alteplase within 3 hours of stroke onset $(p<0.001)$. Pre-stroke modified Rankin Scale (mRS) scores ranged from 0 to 2 , with most patients of both groups having pre-stroke mRS scores of 0 (86\%).

Regarding stroke subtypes, there was a significantly higher percentage of patients with posterior circulation infarction (POCI) in the low-dose group (20\%), while no cases of POCI were present in the standard-dose group ( $p=0.003)$.

There was a significantly higher mean value for the Alberta Stroke Program Early CT (ASPECT) scores in the low-dose group than in the standard-dose group $(6.83 \pm 3.09$ versus $5.55 \pm 2.59, p=0.049)$.

Regarding outcome, favorable outcomes (mRS scores of 0 to 2 ) at 3 months were recorded in $67.5 \%$ of the low-dose group versus $62.5 \%$ of the standard-dose group ( $p=0.631$ ).

Alteplase dose was not a significant predictor of favorable outcome (OR=0.402, $p=0.504$, 95\% CI 0.028-5.824). The only significant predictor of a favorable outcome at 3 months was a NIHSS score $\leq 13$. For each one-degree decrease in NIHSS, there was a 2.338 degree increase in favorable outcomes $(\mathrm{OR}=0.097, p=0.018,95 \%$ CI (0.014-0.673)).

Regarding safety, no cases of SICH were found in the low-dose group. In comparison, 3 cases $(7.5 \%)$ were found in the standard-dose group ( $p=0.077$ ). The overall rate of hemorrhagic transformation was $2.5 \%$ in the low-dose group versus $12.5 \%$ in the standard-dose group. Three cases were parenchymal hemorrhage type 1 (lesion occupying $<30 \%$ with no mass effect) and 3 cases were parenchymal hemorrhage type 2 (lesion occupying $>30 \%$ with definite mass effect) (Table 2).

Mortality at 3 months was $5 \%$ in the low-dose group versus $2.5 \%$ in the standard-dose group $(p=0.556)$. Only 2 patients died in the hospital (one from each group) (Table 3).

Discussion. Low-dose alteplase use in treating acute ischemic stroke is not common in Egypt. This study demonstrated the results of thrombolysis with a low dose in a sample of the Egyptian population. The time from stroke onset to thrombolysis was strikingly different between the low and standard-dose groups. In the low-dose group, $90 \%$ of patients were thrombolysed between 3 and 4.5 hours of stroke onset, while $97.5 \%$ of the standard-dose group patients were thrombolysed within 3 hours of stroke onset. The extended time window ( 3 to 4 and a half hours) in the low-dose group was a strong rationale for using low-dose alteplase, as the increased time could increase hemorrhagic transformation risk. This was evidenced by Wahlgren et $\mathrm{al}^{3}$ and Hacke et $\mathrm{al},{ }^{4}$ who recorded the standard dose efficacy in the extended window ( 3 and 4.5 hours) but found $\mathrm{SICH}$ higher risk in comparison to a 3-hour window $(2.2 \%-2.4 \%$ versus $1.7 \%)$.

In most of the studies comparing low and standard alteplase doses, favorable outcome was considered with a modified Rankin Scale score of 0 to 1 and a score of 0 to 2 represented functional independence. In the current study, a favorable outcome was considered with a score of 0 to 2 at 3 months. Our justification was that with scores of 0 to 2, the patient achieves a state of functional independence, which is considered a good outcome.

In the current study, $67.5 \%$ of patients in the low-dose group had favorable outcomes at 3 months in comparison to $62.5 \%$ of the standard-dose group patients, with no significant difference between both groups. This finding is consistent with the results of Kim et al, ${ }^{17}$ who found that $45.5 \%(n=450)$ of patients who received low-dose alteplase achieved $\mathrm{mRS}$ scores of 0 to 2 at 3 months in comparison to $49 \%(n=1,076)$ of the standard-dose group. In addition, Chao et al, ${ }^{19}$ who studied different doses of alteplase for acute stroke in Chinese patients $(0.6,0.7,0.8$, and $0.9 \mathrm{mg} / \mathrm{kg}$ ), demonstrated that patients with mRS scores of 0 to 2 at 3 months included 53\% ( $n=146)$ of the low-dose (0.6 
$\mathrm{mg} / \mathrm{kg})$ group and $47 \%(\mathrm{n}=367)$ of the standard-dose group $(0.9 \mathrm{mg} \mathrm{kg})$.

In the current study, a binary logistic regression analysis for predictors of favorable outcomes at 3 months revealed that an NIHSS score of $\leq 13$ was the only significant predictor of a favorable outcome at 3 months, and that for each one-degree decrease in NIHSS scores, there was a 2.338-degree increase in favorable outcomes $(\mathrm{OR}=0.097, \quad p=0.018$, 95\% CI: 0.014 to 0.673 ) (Table 4). This result goes with Chao et $\mathrm{al}^{19}$ who stated that an NIHSS score $\leq 8$ was an independent predictor of a good outcome after intravenous alteplase $(\mathrm{OR}=0.37, p=0.0001,95 \% \mathrm{CI})$. The different values of NIHSS scores could be explained by the different scores of favorable outcomes considered - an mRS score of 0 to 1 in Chao et $\mathrm{al}^{19}$ study versus a score of 0 to 2 in the current study.

This analysis revealed that the dose of alteplase was a non-significant predictor of stroke outcome at 3 months (OR=0.402, $p=0.504,95 \%$ CI: 0.028 to 5.824). No patients developed SICH in the low-dose group, in comparison to 3 cases developed $(7.5 \%)$ in the standard-dose group. This result agrees with Anderson et $\mathrm{al}^{20}$ in which fewer major SICH occurred in the low-dose group than in the standard-dose group (1\% versus $2.1 \%$ ). The difference in patients percentage that developed SICH in this study versus the study of Anderson et $\mathrm{al}^{20}$ might be the result of SITS-MOST criteria use for $\mathrm{SICH}$ in the latter study. In addition, Chao et $\mathrm{al}^{19}$ showed that there was no difference between their 2 treatment groups regarding $\mathrm{SICH}$ according to the ECASS definition (5\% in both).

Nguyen et al, ${ }^{21}$ in their comparative study between low-dose and standard-dose alteplase in Vietnam, also documented no difference in the occurrence of SICH (per the ECASS definition) in their standard-dose group compared with their low-dose group (5\% versus $2 \%$ ).

Kim et $\mathrm{al}^{18}$ also reported that no statistically significant differences in the incidence of $\mathrm{SICH}$ between their standard-dose and low-dose groups $(6 \%$ versus $8 \%$ ).

There were no significant differences between low-dose and standard-dose groups regarding mortality at 3 months: there were 2 cases in the low dose group versus one case in the standard-dose group (5\% versus $2.5 \%, p=0.556)$. Most of the studies that compared low and standard rt-PA doses have been compatible with our present study result showing no significant difference between the 2 doses regarding the 3 months mortality. Kim et al, ${ }^{18}$ found that there was no significant difference between the low dose and standard dose $(13 \%$ versus $14 \%)$. Chao et $\mathrm{al}^{19}$ documented a 3 months mortality of $8 \%$ in both 0.6 and $0.9 \mathrm{mg} / \mathrm{kg}$ groups. Sharma et al, ${ }^{22}$ in Singapore documented that there was no significant difference in the 3 months mortality between low and standard doses $(10 \%$ versus $13 \%)$. Anderson et $\mathrm{al}^{20}$ also showed that mortality at 90 days did not differ significantly between the 2 groups (8.5\% and $10.3 \%$ ).

Yang et $\mathrm{a}^{23}$ studied a comparison between the 2 groups where the mortality in the $0.6 \mathrm{mg} / \mathrm{kg}$ dose group had a non-significantly higher incidence than that of the standard-dose group ( $4.3 \%$ versus $1.6 \%$ in the 0.9 $\mathrm{mg} / \mathrm{kg}$ dose group, $p=0.792$ ). The mortality in the 0.6 $\mathrm{mg} / \mathrm{kg}$ dose group was higher than that in the $0.9 \mathrm{mg} /$ $\mathrm{kg}$ dose group ( $4.3 \%$ versus $1.6 \%$, respectively; $p>0.05$ )

Nguyen et $\mathrm{al}^{21}$ was the only study to show a significant difference in the mortality rate at 3 months, mortality rates of $2 \%$ in the low-dose group and $12 \%$ in the standard-dose group.

Study limitations. First, the sample size was small because of the following factors: public awareness of stroke symptoms and the relevant time window is still deficient in our region, so many stroke patients arrive at the hospital after the thrombolytic window. In addition, thrombolytic therapy was recently introduced to our center in 2017 at a high cost (which is still not covered by health insurance), so many patients cannot afford it. Some other studies recruited small numbers of patients, like Nguyen et $\mathrm{al}^{21}$ who included 48 in the low-dose group versus 73 standard-dose patients; Sharma et al, ${ }^{22}$ who included 48 low-dose patients versus 32 patients receiving the standard dose; and Zhou et $\mathrm{al}^{24}$ who included 23 patients receiving a low dose). Second, the alteplase dose selection was not randomized. Also, both groups were not balanced regarding to ASPECTS score and POCI. Finally, the stroke team that conducted the outcome assessments was not blinded to the treatments, raising the possibility of observer bias.

In conclusion, the present study showed that there was no statistically significant difference between low and standard alteplase doses regarding either safety or outcome. Taking into consideration the economic burden of the treatment, low-dose alteplase $(0.6 \mathrm{mg} / \mathrm{kg})$ could be a practical alternative for Egyptian populations with acute ischemic stroke especially in 3-4.5 hours window. This study compares between different doses of alteplase in acute ischemic stroke treatment in a big country like Egypt where utilization of reperfusion therapies for stroke remains $<1 \%$ Zakaria et $\mathrm{al}^{25}$ Therefore, additional confirmation with randomized controlled trials in Egyptian patients is necessary. 
Acknowledgment. The authors would like to acknowledge proofreadingservices.com for English language editing of the manuscript

\section{References}

1. Macrez R, Ali C, Toutirais O, Le Mauff B, Defer G, Dirnagl $\mathrm{U}$, et al. Stroke and the immune system: from pathophysiology to new therapeutic strategies. Lancet Neurology 2011; 10: 471-480.

2. National Institute of Neurological Disorders and Stroke rt-PA Stroke Study. Tissue plasminogen activator for acute ischemic stroke. N Engl J Med 1995; 333: 1581-1587.

3. Wahlgren N, Ahmed N, Dávalos A, Ford GA, Grond M, Hacke W, et al. Thrombolysis with alteplase for acute ischemic stroke in the Safe Implementation of Thrombolysis in StrokeMonitoring Study (SITS-MOST): an observational study. Lancet 2007; 369: 275-282.

4. Hacke W, Kaste M, Bluhmki E, Brozman M, Dávalos A, Guidetti D, et al. Thrombolysis with alteplase 3 to 4.5 hours after acute ischemic stroke (ECASS III). N Engl J Med 2008; 359: 1317-1329.

5. Chiu D, Krieger D, Villar-Cordova C, Kasner SE, Morgenstern $\mathrm{LB}$, Bratina PL, et al. Intravenous tissue plasminogen activator for acute ischemic stroke: feasibility, safety, and efficacy in the first year of clinical practice. Stroke 1998; 29: 18-22.

6. Liu MD, Ning WD, Wang RC, Chen W, Yang Y, Lin Y, et al. Low-dose versus standard-dose tissue plasminogen activator in acute ischemic stroke in Asian populations: a meta-analysis. Medicine 2015; 94: e2412.

7. Yamaguchi T, Mori E, Minematsu K, Nakagawara J, Hashi K, Saito I et al: Alteplase at $0.6 \mathrm{mg} / \mathrm{kg}$ for acute ischemic stroke within 3 hours of onset: Japan Alteplase Clinical Trial (J-ACT). Stroke 2006; 37: 1810-1815.

8. Nakagawara J, Minematsu K, Okada Y, Tanahashi N, Nagahiro $\mathrm{S}$, Mori E, et al. Thrombolysis with $0.6 \mathrm{mg} / \mathrm{kg}$ intravenous alteplase for acute ischemic stroke in routine clinical practice: the Japan post-Marketing Alteplase Registration Study (J-MARS). Stroke 2010; 41: 1984-1989.

9. Mori E, Yoneda Y, Tabuchi M, Yoshida T, Ohkawa S, Ohsumi $Y$, et al. Intravenous recombinant tissue plasminogen activator in acute carotid artery territory stroke. Neurology 1992; 42: 976-976.

10. Yamaguchi T, Mori E, Minematsu K, Nakagawara J, Hashi K, Saito I, et al. Alteplase at $0.6 \mathrm{mg} / \mathrm{kg}$ for acute ischemic stroke within 3 hours of onset: Japan Alteplase Clinical Trial (J-ACT). Stroke 2006; 37: 1810-1815.

11. Abd Allah F, Baligh E, Ibrahim M. Clinical relevance of carotid atherosclerosis among Egyptians: a 5-year retrospective analysis of 4,733 subjects. Neuroepidemiology 2010; 35: 275-27s9.

12. Zakaria MF, Aref H, Abd ElNasser A, Fahmy N, Tork M, Fouad M, et al. Egyptian experience in increasing utilization of reperfusion therapies in acute ischemic stroke. Int J Stroke 2018; 13: 525-529.
13. Powers WJ, Rabinstein AA, Ackerson, T., et al. 2018 guidelines for the early management of patients with acute ischemic stroke: a guideline for healthcare professionals from the American Heart Association/American Stroke Association. Stroke 2018; 49: e46-e99.

14. Barber PA, Demchuk AM, Zhang J, Adeoye OM, Bambakidis NC, Becker K, et al. The validity and reliability of a novel quantitative CT score in predicting outcome in hyperacute stroke prior to thrombolytic therapy. Lancet 2000; 355: 1670-1674.

15. Bamford J, Sandercock P, Dennis M, Burn J, Warlow C. Classification and natural history of clinically identifiable subtypes of cerebral infarction. Lancet 1991; 337: 1521-1526.

16. Adams H, Bendixen B, Kappelle L. Classification of subtype of acute ischemic stroke Definitions for use in a multicenter clinical trial. TOAST Trial of Org 10172 in Acute Stroke Treatment. Stroke 1993; 24: 35-41.

17. Hage V. "The NIH stroke scale: a window into neurological status". Nursing Spectrum 2011; 24: 44-49.

18. Kim B J, Han MK, Park TH, Park SS, Lee KB, Lee BC, et al. Low-versus standard-dose alteplase for ischemic strokes within 4.5 hours: a comparative effectiveness and safety study. Stroke 2015; 46: 2541-2548.

19. Chao AC, Liu CK, Chen CH, Lin HJ, Liu CH, Jeng JS, et al. Different doses of recombinant tissue-type plasminogen activator for acute stroke in Chinese patients. Stroke 2014; 45: 2359-2365.

20. Anderson CS, Robinson T, Lindley RI, Arima H, Lavados PM, Lee T, et al. Low-dose versus standard-dose intravenous alteplase in acute ischemic stroke. N Engl J Med 2016; 374: 2313-2323.

21. Nguyen TH, Truong AL, Ngo MB, Bui CT, Dinh QV, Doan TC, et al. Patients with thrombolysed stroke in Vietnam have an excellent outcome: results from the Vietnam Thrombolysis Registry. Eur J Neurol 2010; 17: 1188-1192.

22. Sharma VK, Kawnayn G, Sarkar N. Acute ischemic stroke: comparison of low-dose and standard-dose regimes of tissue plasminogen activator. Expert Rev Neurother 2013; 13: 895-902.

23. Yang J, Yu F, Liu H, An H, Xiong R, Huang D. A retrospective study of thrombolysis with $0.6 \mathrm{mg} / \mathrm{kg}$ recombinant tissue plasminogen activator (rt-PA) in mild stroke. Sci Rep 2016; 6: 31344.

24. Zhou XY, Wanga SS, Collins ML, Davis SM, Yan B. Efficacy and safety of different doses of intravenous tissue plasminogen activator in Chinese patients with ischemic stroke. J Clin Neurosci 2010; 17: 988-992.

25. Zakaria MF, Aref H, Abd ElNasser A, Fahmy N, Tork MA, Fouad MM, et al. Egyptian experience in increasing utilization of reperfusion therapies in acute ischemic stroke. Int J Stroke 2018; 13: 525-529. 